ano 16 - n. 63। janeiro/março - 2016

Belo Horizonte I p. 1-262 I ISSN 1516-3210

A\&C - R. de Dir. Administrativo \& Constitucional

Revista de Direito ADMINISTRATIVO \& CONSTITUCIONAL

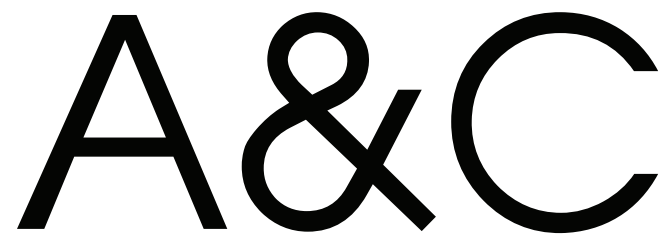




\section{A\&C - REVISTA DE DIREITO ADMINISTRATIVO \& CONSTITUCIONAL}

IPDA

Instituto Paranaense

de Direito Administrativo
ROMEU DELPE

BACELLAR

(c) 2016 Editora Fórum Ltda.

Todos os direitos reservados. É proibida a reprodução total ou parcial, de qualquer forma ou por qualquer meio eletrônico ou mecânico, inclusive através de processos xerográficos, de fotocópias ou de gravação, sem permissão por escrito do possuidor dos direitos de cópias (Lei no 9.610, de 19.02.1998).

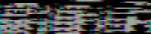

Luís Cláudio Rodrigues Ferreira

Presidente e Editor

Av. Afonso Pena, 2770 - 15a andar - Savassi - CEP 30130-012 - Belo Horizonte/MG - Brasil - Tel.: 08007043737 www.editoraforum.com.br / E-mail: editoraforum@editoraforum.com.br

Impressa no Brasil / Printed in Brazil / Distribuída em todo o Território Nacional

Os conceitos e opiniões expressas nos trabalhos assinados são de responsabilidade exclusiva de seus autores.

\begin{tabular}{|c|c|}
\hline A246 & $\begin{array}{l}\text { A\&C : Revista de Direito Administrativo \& } \\
\text { Constitucional. - ano 3, n. 11, (jan./mar. } \\
\text { 2003)- . - Belo Horizonte: Fórum, 2003- }\end{array}$ \\
\hline & 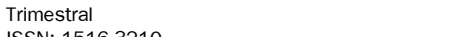 \\
\hline & $\begin{array}{l}\text { Ano 1, n. 1, } 1999 \text { até ano 2, n. 10, } 2002 \text { publicada } \\
\text { pela Editora Juruá em Curitiba }\end{array}$ \\
\hline & $\begin{array}{l}\text { 1. Direito administrativo. } 2 \text {. Direito constitucional. } \\
\text { I. Fórum. }\end{array}$ \\
\hline & $\begin{array}{l}\text { CDD: } 342 \\
\text { CDU: } 342.9\end{array}$ \\
\hline
\end{tabular}

Coordenação editorial: Leonardo Eustáquio Siqueira Araújo Capa: Igor Jamur

Projeto gráfico e diagramação: Walter Santos

\section{Periódico classificado no Estrato A1 do Sistema Qualis da CAPES - Área: Direito.}

Revista do Programa de Pós-graduação do Instituto de Direito Romeu Felipe Bacellar (Instituição de Pesquisa e Pós-Graduação), em convênio com o Instituto Paranaense de Direito Administrativo (entidade associativa de âmbito regional filiada ao Instituto Brasileiro de Direito Administrativo). A linha editorial da $A \& C$ - Revista de Direito Administrativo \& Constitucional segue as diretrizes do Programa de Pós-Graduação do Instituto de Direito Romeu Felipe Bacellar em convênio com o Instituto Paranaense de Direito Administrativo. Procura divulgar as pesquisas desenvolvidas na área de Direito Constitucional e de Direito Administrativo, com foco na questão da efetividade dos seus institutos não só no Brasil como no direito comparado, com ênfase na questão da interação e efetividade dos seus institutos, notadamente América Latina e países europeus de cultura latina.

A publicação é decidida com base em pareceres, respeitando-se o anonimato tanto do autor quanto dos pareceristas (sistema double-blind peer review).

Desde o primeiro número da Revista, $75 \%$ dos artigos publicados (por volume anual) são de autores vinculados a pelo menos cinco instituições distintas do Instituto de Direito Romeu Felipe Bacellar.

A partir do volume referente ao ano de 2008 , pelo menos $15 \%$ dos artigos publicados são de autores filiados a instituições estrangeiras.

Esta publicação está catalogada em:

- Ulrich's Periodicals Directory

- RVBI (Rede Virtual de Bibliotecas - Congresso Nacional)

- Library of Congress (Biblioteca do Congresso dos EUA)

A\&C - Revista de Direito Administrativo \& Constitucional realiza permuta com as seguintes publicações: - Revista da Faculdade de Direito, Universidade de São Paulo (USP), ISSN 0303-9838

- Rivista Diritto Pubblico Comparato ed Europeo, ISBN/EAN 978-88-348-9934-2 
Diretor-Geral

Romeu Felipe Bacellar Filho

Diretor Editorial

Paulo Roberto Ferreira Motta

Editores Acadêmicos Responsáveis

Daniel Wunder Hachem

Ana Cláudia Finger

Assessor Editorial

Felipe Klein Gussoli

\section{Conselho Editorial}

Adilson Abreu Dallari (PUC-SP) Juan Pablo Cajarville Peluffo (Universidad de La República - Uruguai) ardo Schier (Instituto Bacellar) Justo J. Reyna (Universidad Nacional del Litoral - Argentina)

Alice Gonzalez Borges (UFBA) Juarez Freitas (UFRGS)

Carlos Ari Sundfeld (FGV-SP) Luís Enrique Chase Plate (Universidad Nacional de Asunción - Paraguai)

Carlos Ayres Britto (UFSE) Marçal Justen Filho (UFPR)

Adriana da Costa Ricardo Schier (Instituto Bacellar)
Alice Gonzalez Borges (UFBA)

Marcelo Figueiredo (PUC-SP)

Márcio Cammarosano (PUC-SP)

Carlos Delpiazzo (Universidad de La República - Uruguai) Cármen Lúcia Antunes Rocha (PUC Minas) Célio Heitor Guimarães (Instituto Bacellar) Celso Antônio Bandeira de Mello (PUC-SP) Clèmerson Merlin Clève (UFPR) Clovis Beznos (PUC-SP) Edgar Chiuratto Guimarães (Instituto Bacellar) Maria Cristina Cesar de Oliveira (UFPA)

Nelson Figueiredo (UFG)

Odilon Borges Junior (UFES)

Pascual Caiella (Universidad de La Plata - Argentina)

Emerson Gabardo (UFPR)

Paulo Eduardo Garrido Modesto (UFBA)

Paulo Henrique Blasi (UFSC)

Enrique Silva Cimma (Universidad de Chile - Chile) Eros Roberto Grau (USP)

Irmgard Elena Lepenies (Universidad Nacional del Litoral - Argentina) de La Coruña - Espanha)

Pedro Paulo de Almeida Dutra (UFMG)

Regina Maria Macedo Nery Ferrari (UFPR)

Rogério Gesta Leal (UNISC)

Rolando Pantoja Bauzá (Universidad Nacional de Chile - Chile)

Sergio Ferraz (PUC-Rio)

Valmir Pontes Filho (UFCE)

José Eduardo Martins Cardoso (PUC-SP)

José Luís Said (Universidad de Buenos Aires - Argentina) José Mario Serrate Paz (Universidad de Santa Cruz - Bolívia)

Yara Stroppa (PUC-SP)

\section{Homenagem Especial}

Guillermo Andrés Muñoz (in memoriam) Jorge Luís Salomoni (in memoriam) Julio Rodolfo Comadira (in memoriam) Lúcia Valle Figueiredo (in memoriam)

Manoel de Oliveira Franco Sobrinho (in memoriam) Paulo Neves de Carvalho (in memoriam) 


\title{
Edifícios públicos sustentáveis: discricionariedade administrativa ou dever constitucional e legal?
}

\section{Carlos Augusto Alcântara Machado}

Professor de Direito Constitucional dos Cursos de Graduação e Pós-Graduação Stricto Sensu da Universidade Federal de Sergipe - UFS e da Universidade Tiradentes - Unit (Aracaju - SE, Brasil). Doutor em Direito pela Pontifícia Universidade Católica de São Paulo - PUC/SP. Mestre em Direito pela Universidade Federal do Ceará. Procurador de Justiça em Sergipe. E-mail: <cmachado@infonet.com.br>.

\section{Augusto César Leite de Resende}

Professor de Direito Constitucional dos Cursos de Graduação e Pós-Graduação Lato Sensu da Faculdade de Administração e Negócios de Sergipe - Fanese (Aracaju - SE, Brasil). Mestre em Direito Econômico e Socioambiental pela Pontifícia Universidade Católica do Paraná PUCPR. Promotor de Justiça em Sergipe. E-mail: <aclresende@bol.com.br>.

\begin{abstract}
Resumo: A construção e o uso de prédios públicos provocam sérios efeitos negativos no meio ambiente, porque é utilizada grande quantidade de recursos naturais na sua edificação e têm elevado impacto no consumo de energia elétrica e água e na produção de resíduos sólidos. Por essa razão, o presente artigo tem como objetivo principal apresentar, a partir de uma pesquisa doutrinária e legislativa, argumentos favoráveis no sentido de que a construção e o uso de edifícios públicos devem ocorrer em consonância com o desenvolvimento sustentável. Por isso, analisar-se-á o conceito de desenvolvimento sustentável, o seu reconhecimento enquanto direito fundamental da pessoa humana, a ideia de construções verdes e o dever estatal de edificarem prédios públicos sustentáveis.
\end{abstract}

Palavras-chave: Sustentabilidade. Construções verdes. Edifícios públicos. Obrigação estatal.

Sumário: 1 Introdução - 2 Desenvolvimento sustentável - 3 Direito fundamental ao desenvolvimento sustentável - $\mathbf{4}$ Edificações públicas sustentáveis - $\mathbf{5}$ Considerações finais - Referências

\section{Introdução}

O tema do presente trabalho científico se inspirou no fato de que o atual ritmo de produção e consumo está esgotando as reservas naturais e colocando em xeque a existência da vida no planeta, de modo que urge solucionar a contradição existente entre crescimento econômico e preservação do meio ambiente, uma vez que o capitalismo, em regra, busca sempre o crescimento ilimitado e despreza os limites da natureza, razão pela qual é necessária a promoção do desenvolvimento sustentável. 
A construção e o uso de prédios públicos têm importante papel na degradação do meio ambiente, porque utilizam uma grande quantidade de recursos naturais na edificação e o seu uso tem elevado impacto no consumo de energia elétrica e água e na produção de resíduos sólidos.

A tomada de consciência da crise ecológica da modernidade ensejou uma mudança de percepção da relação do homem com a natureza, inicialmente, na comunidade acadêmica, mas, posteriormente, na sociedade civil e, dentro desse contexto, surgem as chamadas construções sustentáveis, concebidas para fazer o uso racional de recursos naturais e alterar o mínimo possível o ambiente no qual estão inseridas.

No entanto, a construção e o uso de edifícios públicos sustentáveis são uma obrigação do Estado ou mera liberalidade da Administração Pública consciente de sua responsabilidade socioambiental perante a sociedade? Nesse diapasão, pretendese, ao longo deste trabalho, demonstrar que o Estado é constitucionalmente obrigado a somente edificar empreendimentos sustentáveis.

Primeiramente, discutir-se-á o conceito de desenvolvimento sustentável. Posteriormente, tratar-se-á da inclusão do desenvolvimento sustentável no rol dos direitos fundamentais consagrados na Carta Magna. A relação entre sustentabilidade e a construção e o uso de prédios públicos e o papel estatal na promoção do desenvolvimento sustentável será analisada em seguida.

\section{Desenvolvimento sustentável}

Os seres humanos extraem, desde os tempos primevos, recursos da natureza para satisfazer suas necessidades, gerando assim efeitos negativos no meio ambiente, os quais, inicialmente, eram totalmente absorvidos pelo ecossistema, já que havia uma pequena quantidade de pessoas no planeta e as sociedades primitivas eram baseadas na agricultura de subsistência.

Contudo, a modernidade, que Anthony Giddens conceitua como o "estilo, costume de vida ou organização social que emergiram na Europa a partir do século XVII e que ulteriormente se tornaram mais ou menos mundiais em sua influência", ${ }^{1}$ substituiu as sociedades primitivas, cujas formas de produção eram baseadas na agricultura, pela sociedade moderna, da qual o capitalismo e a industrialização são duas de suas dimensões.

A industrialização e os avanços científicos e tecnológicos ocorridos após a Segunda Guerra Mundial transformaram a sociedade ocidental moderna em uma sociedade de consumo. A sociedade moderna se caracteriza por ser um grupo social em estágio avançado de desenvolvimento industrial, com grande circulação

GIDDENS, Anthony. As consequências da modernidade. Tradução de Raul Fiker. São Paulo: Unesp, 1991. p. 11. 
e consumo de bens e serviços oferecidos graças a uma produção intensiva, pois o homem contemporâneo tem uma necessidade ilimitada de adquirir e usar inúmeros bens e serviços. ${ }^{2}$

Na sociedade de consumo, os produtos não são fabricados em função do seu respectivo valor de uso ou da sua utilidade, mas antes em função de seu perecimento calculado, da sua morte, ${ }^{3}$ ou seja, os bens e serviços inseridos no mercado de consumo têm vida curta e sua morte é programada. É a chamada "obsolescência programa", estratégia utilizada por empresas para diminuir o ciclo de vida dos produtos objetivando a sua substituição por novos bens e serviços, fazendo, com isso, aumentar os lucros através das vendas constantes e maiores de seus produtos.

Aduz Zygmunt Bauman que "os mercados de consumo se concentram na desvalorização imediata de suas antigas ofertas, a fim de limpar a área da demanda pública para que novas ofertas a preencham". ${ }^{4}$ Assim, por meio da inserção no mercado de novos bens e serviços, produzem carências e desejos nas pessoas, pois os indivíduos passam a ser julgados por aquilo que consomem, vestem ou calçam, pelos locais que frequentam, pelos bens materiais que possuem e mostram aos outros membros da sociedade.

Os indivíduos são incentivados pelos diversos veículos de publicidade a consumirem desenfreadamente, a adquirir produtos não essenciais e desnecessários e, nesse caso, a "publicidade realiza o prodígio de um orçamento considerável gasto com o único fim, não de acrescentar, mas de tirar o valor de uso dos objectos, de diminuir o seu valor/tempo, sujeitando-se ao valor/moda e à renovação acelerada", ${ }^{5}$ já que incute na mente das pessoas que os seus produtos se tornaram defasados, induzindo-as, assim, a adquirir novos produtos. Enfim, a sobrevivência da sociedade de consumo depende da criação de desejos e carências por novas mercadorias. ${ }^{6}$

É preciso, pois, embutir na consciência dos homens a necessidade de adquirir novos bens e serviços, a fim de que o produto, ao ser inserido no mercado, seja ao máximo consumido e, em seguida, substituído por outra mercadoria.

0 processo de desenvolvimento econômico e o avanço industrial, em especial após a segunda metade do século XX, intensificaram os impactos negativos da interferência do ser humano no meio ambiente, uma vez que é a natureza quem fornece a matéria-prima dos produtos inseridos no mercado de consumo, colocando em risco o planeta e a sobrevivência humana. ${ }^{7}$

\footnotetext{
2 FAJARDO, Elias. Consumo consciente, comércio justo: conhecimento e cidadania como fatores econômicos. Rio de Janeiro: Senac Nacional, 2010. p. 14.

3 BOUDRILLARD, Jean. A sociedade de consumo. 3. ed. Lisboa: Edições 70, 2011. p. 44.

4 BAUMAN, Zygmunt. Vida para o consumo: a transformação das pessoas em mercadoria. Rio de Janeiro: Zahar, 2008. p. 128.

5 BOUDRILLARD, Jean. A sociedade de consumo. 3. ed. Lisboa: Edições 70, 2011. p. 45.

6 PORTILHO, Fátima. Sustentabilidade ambiental, consumo e cidadania. 2. ed. São Paulo: Cortez, 2010. p. 21-22.

7 GIDDENS, Anthony. As consequências da modernidade. Tradução de Raul Fiker. São Paulo: Unesp, 1991. p. 71.
} 
O consumo é uma necessidade biológica e vital do ser humano, pois consumimos para viver. ${ }^{8}$ Por outro lado, o consumismo, entendido como um comportamento humano destinado à satisfação pessoal ou à exibição pública através da aquisição de bens e mercadorias, ${ }^{9}$ é um dos principais problemas da sociedade moderna, porque os atuais padrões de consumo e estilos de vida estão nas bases da crise ambiental da atualidade.

Nos dias atuais, os indivíduos passam a consumir com os olhos e emoções voltados apenas para eles mesmos, num ato extremamente individualista e egoísta, sem se preocupar com as consequências socioambientais de suas decisões de consumo. Vive-se uma cultura de consumismo. Enfim, as nossas atividades econômicas, estilos de vida e hábitos de consumo estão destruindo a biodiversidade e o planeta a um ponto quase irreversível, ${ }^{10}$ razão pela qual devemos reduzir ao máximo o impacto de nossas atividades no meio ambiente.

A relação do homem com a natureza é denominada por Marx de metabolismo. Tal interação se dá através do trabalho e o trabalho real, por sua vez, é a apropriação da natureza para a satisfação das necessidades humanas, a atividade através da qual o metabolismo entre o homem e a natureza é mediado. ${ }^{11} \mathrm{O}$ ser humano passou da submissão à natureza para a dominação da natureza, exigindo-se nos dias atuais uma relação harmônica entre o ser humano e o meio ambiente.

Aliás, Karl Marx já demonstrava no século XIX preocupação com a mudança de postura do homem com a natureza, quando no volume 1 de Capital desenvolveu uma crítica da exploração capitalista do solo, ao ressaltar que a agricultura capitalista de larga escala perturbava a relação metabólica entre o homem e a terra, afetando demasiadamente a fertilidade do solo e, consequentemente, o ser humano. ${ }^{12}$

A crise ecológica vem das bases de nossa percepção, porque com a modernidade os homens passaram a não mais enxergar a natureza como um ser vivo, além de não enxergarem também que são inseparáveis dela e da Terra..$^{13}$ Deve-se superar a ideia mecanicista-cartesiana de que a compreensão do comportamento do todo deveria partir das propriedades de suas partes, a partir de uma visão sistêmica em que as propriedades essenciais de um organismo são propriedades do todo e que somente podem ser entendidas dentro do contexto do todo mais amplo. ${ }^{14}$

8 BAUMAN, Zygmunt. Vida para o consumo: a transformação das pessoas em mercadoria. Rio de Janeiro: Zahar, 2008. p. 37

9 PORTILHO, Fátima. Sustentabilidade ambiental, consumo e cidadania. 2. ed. São Paulo: Cortez, 2010. p. 25.

10 CAPRA, Fritoj. As conexões ocultas: ciência para uma vida sustentável. São Paulo: Cultrix, 2005. p. 157.

11 FOSTER, John Bellamy. A ecologia em Marx: materialismo e natureza. Rio de Janeiro: Civilização Brasileira, 2005. p. 222.

12 FOSTER, John Bellamy. A ecologia em Marx: materialismo e natureza. Rio de Janeiro: Civilização Brasileira, 2005. p. 219.

13 HARDING, Stephan. Terra viva: ciência, intuição e a evolução de Gaia - Para uma nova compreensão da vida em nosso planeta. São Paulo: Cultrix, 2008. p. 37.

14 CAPRA, Fritoj. A teia da vida: uma nova compreensão científica dos sistemas vivos. São Paulo: Cultrix, 2006. p. $40-41$. 
A crise ambiental tem raízes éticas, de modo que a solução para a questão ecológica não é apenas técnica, mas exige também uma mudança do próprio ser humano, da sua forma de pensar e compreender a complexidade da vida e do mundo, no sentido de reconhecer que o homem e a natureza estão interligados e são interdependentes e inseparáveis, ${ }^{15}$ pois assim o ser humano conseguirá mudar seu comportamento para uma postura de fraternidade em relação ao meio ambiente.

Tem-se a necessidade de mudanças de paradigmas e de percepção, isto é, da forma de pensar e dos nossos valores, a fim de se reconhecer uma visão holística do mundo, no sentido de que seres humanos e a natureza estão interligados e são interdependentes. ${ }^{16} \mathrm{~A}$ interdependência e a interconexão entre ser humano e natureza é flagrante, porque não há possibilidade de se separar o homem da natureza, pelo simples fato de que é a natureza que fornece a vida aos seres humanos.

Sendo assim, é mister a compatibilização do desenvolvimento com a proteção da natureza, mediante a promoção do desenvolvimento sustentável, como instrumento de garantia não somente da vida biológica, mas da vida com dignidade e qualidade para as presentes e futuras gerações. ${ }^{17}$

Não se pode conceber o crescimento econômico como sinônimo de desenvolvimento, porque o crescimento é mero "aumento do produto nacional em termos globais ou per capita num período determinado" ${ }^{18}$ sem promover, necessariamente, transformações qualitativas no bem-estar humano.

O desenvolvimento, por outro lado, é sempre um processo que faz as condições de vida se elevarem continuamente, enquanto que crescimento é apenas um "surto" em que cessada a causa do crescimento, retorna-se rapidamente ao status quo ante. ${ }^{19}$ Ademais, o sentido de desenvolvimento vai além do conceito de desenvolvimento puramente econômico, visto que pressupõe uma aproximação centrada nos direitos humanos, em que se dever ter sempre em mente a paz, a economia, o meio ambiente, a justiça e a democracia. ${ }^{20}$

Logo, a concepção de desenvolvimento deve estar intimamente jungida à concretização da dignidade da pessoa humana e à defesa do meio ambiente, de forma que o desenvolvimento deve ser perseguido sem provocar danos ao meio ambiente

15 MORIN, Edgar. A via para o futuro da humanidade. Rio de Janeiro: Bertrand Brasil, 2013. p. 104.

16 CAPRA, Fritoj. A teia da vida: uma nova compreensão científica dos sistemas vivos. São Paulo: Cultrix, 2006. p. 25-26.

17 DALY, Herman E. Economics in a full world. Scientific American, EUA, v. 293, n. 3, p. 100-107, set. 2005. p. 100.

18 GARBADO, Emerson. Interesse público e subsidiariedade: o Estado e a sociedade civil para além do bem e do mal. Belo Horizonte: Fórum, 2009. p. 243.

19 GARBADO, Emerson. Interesse público e subsidiariedade: o Estado e a sociedade civil para além do bem e do mal. Belo Horizonte: Fórum, 2009. p. 244.

20 RISTER, Carla Abrantkski. Direito ao desenvolvimento: antecedentes, significados e consequências. São Paulo: Renovar, 2007. p. 56. 
ou, ao menos, com o mínimo de impactos negativos na natureza, promovendo, assim, o desenvolvimento sustentável.

A expressão "desenvolvimento sustentável" foi publicamente utilizada pela primeira vez em 1979 no Simpósio das Nações Unidas sobre as Inter-relações entre Recursos, Ambiente e Desenvolvimento. Contudo, é o Relatório Brundtland, denominado Nosso futuro comum, ${ }^{21}$ da Comissão Mundial sobre Meio Ambiente e Desenvolvimento, de 1987, que apresenta uma das definições mais conhecidas sobre desenvolvimento sustentável. Diz o Relatório Brundtland que desenvolvimento sustentável é aquele desenvolvimento que satisfaz as necessidades presentes, sem comprometer a capacidade das gerações futuras de suprir suas próprias necessidades.

A Conferência das Nações Unidas sobre Meio Ambiente e Desenvolvimento (ECO-92), realizada na cidade do Rio de Janeiro em junho de 1992, valorizou o direito ao desenvolvimento em harmonia com a proteção do meio ambiente. De fato, o Princípio 4 da Declaração do Rio sobre Meio Ambiente e Desenvolvimento ${ }^{22}$ estabelece que "a proteção ambiental constituirá parte integrante do processo de desenvolvimento e não pode ser considerada isoladamente deste" e, em seu Princípio 25, ressalta que o desenvolvimento e a proteção ambiental são interdependentes e indivisíveis. Desse modo, não se pode falar em desenvolvimento que não seja sustentável.

Verifica-se, assim, que o desenvolvimento sustentável procura conciliar o progresso econômico com o meio ambiente, de modo que as atividades humanas, em especial as de produção e consumo, sejam executadas dentro da capacidade de resiliência da natureza, objetivando garantir a perenidade dos recursos naturais e evitar que a fruição do necessário à satisfação das necessidades da presente geração impeça as futuras gerações de terem as suas próprias necessidades satisfeitas em decorrência da degradação ambiental.

O conceito de desenvolvimento sustentável é, apesar de largamente indeterminado, tridimensional. Segundo Ignacy Sachs, o desenvolvimento sustentável fundamenta-se sobre três pilares ou dimensões, quais sejam, o social, o econômico e o ambiental. ${ }^{23}$

A sustentabilidade econômica impõe eficiência social na alocação e gestão de recursos públicos; a sustentabilidade social exige um processo de desenvolvimento que promova a justiça redistributiva e a maximização da eficácia dos direitos fundamentais sociais e, por fim, a sustentabilidade ambiental pugna pela implementação

\footnotetext{
21 COMISSÃO MUNDIAL SOBRE MEIO AMBIENTE E DESENVOLVIMENTO. Nosso futuro comum. 2. ed. Rio de Janeiro: Editora da Fundação Getúlio Vargas, 1991.

22 MINISTÉRIO DO MEIO AMBIENTE. Declaração do Rio sobre meio ambiente e desenvolvimento. Disponível em: <www.mma.gov.br/port/sdi/ea/documentos/convs/decl_rio92.pdf>. Acesso em: 10 mar. 2015.

23 SACHS, Ignacy. Primeiras intervenções. In: NASCIMENTO, Elimar Pinheiro do; VIANA, João Nildo. Dilemas e desafios do desenvolvimento sustentável no Brasil. Rio de Janeiro: Garamond, 2007. p. 22-23.
} 
de uma justiça ambiental intergeracional, preocupando-se com os impactos negativos das atividades humanas no meio ambiente, de modo que o desenvolvimento deve permitir às gerações futuras o acesso a um meio ambiente sadio e necessário à qualidade de vida.

Ademais, a Conferência das Nações Unidas sobre o Desenvolvimento Sustentável (RIO +20), realizada na cidade do Rio de Janeiro em junho de 2012, reconheceu que são imprescindíveis a integração e a realização dos pilares econômico, social e ambiental para a concretização do desenvolvimento sustentável. ${ }^{24}$

Nesse diapasão, a concepção de desenvolvimento necessita se compatibilizar com a concretização da dignidade da pessoa humana e a defesa do meio ambiente, de forma que o desenvolvimento deve ser perseguido sem provocar danos ao meio ambiente ou, ao menos, com o mínimo de impactos negativos na natureza, promovendo, assim, o que se convencionou denominar de desenvolvimento sustentável.

\section{Direito fundamental ao desenvolvimento sustentável}

Não se desconhece que no campo da explicitação, desenvolvimento e garantia dos direitos fundamentais ou direitos humanos fundamentais, para utilizar uma expressão mais abrangente, discorre-se sobre o tema, já há algumas décadas, identificando os direitos especificamente apresentados, agrupados em fases, gerações ou dimensões.

Nesse passo, ensina Paulo Bonavides que os franceses do século XVIII apresentaram o lema revolucionário do conhecido evento epocal em três princípios cardeais (liberté, égalité, fraternité), profetizando a sequência histórica da institucionalização dos direitos fundamentais. ${ }^{25}$

Assim, os ordenamentos jurídicos da modernidade consagraram, num primeiro estágio, os direitos civis e políticos, expressando compromisso com o valor liberdade e num segundo momento evolutivo, garantiram os direitos sociais, econômicos e culturais, desta feita com especial ênfase no princípio igualdade.

Todavia, o tríptico revolucionário francês estava ainda incompleto.

Foi a partir da conhecida "Lição Inaugural" com o título Pour les droits de l'Homme de la Troisième Génération: Les Droits de solidarité, apresentada em Estrasburgo (2.7.1979), no Instituto Internacional dos Direitos do Homem, e ministrada pelo então Diretor da Divisão de Direitos do Homem e da Paz, da Unesco, Karel Vasak, que a teorização mais elaborada dos direitos fundamentais em três gerações dos direitos veio a lume, objeto de formulação desde o ano de $1977 .{ }^{26}$

\footnotetext{
24 ORGANIZAÇÃO DAS NAÇÕES UNIDAS. Resolução 66/288. O futuro que queremos. Disponível em: <http:// www.un.org/ga/search/view_doc.asp?symbol=A/RES/66/288\&Lanh=E>. Acesso em: 3 mar. 2015.

25 BONAVIDES, Paulo. Curso de direito constitucional. 26. ed. São Paulo: Malheiros, 2011. p. 562.

26 ANJOS FILHO, Robério Nunes dos. Direito ao desenvolvimento. São Paulo: Saraiva, 2013. p. 99.
} 
Naquela clássica aula magna, o jurista tcheco-francês apresentou os direitos de terceira geração, como os que se assentam na fraternidade, caracterizados por transcender a esfera da proteção jurídica das pessoas enquanto indivíduos e até mesmo quando organizadas em grupos ou segmentos.

Exatamente no contexto de direitos de terceira dimensão que se apresenta o direito ao desenvolvimento sustentável fundamentado no valor/princípio da fraternidade, como apregoava Karel Vasak, ou na solidariedade, como prefere EtienneRichard Mbaya. ${ }^{27}$

O desenvolvimento sustentável, enquanto direito fundamental da pessoa humana, foi consagrado pela primeira vez em um documento normativo internacional pela Carta Africana de Direito Humanos e dos Povos, aprovada pela Conferência Ministerial da Organização da Unidade Africana (OUA) em Banjul, Gâmbia, em janeiro de 1981, e adotada pela XVIII Assembleia dos Chefes de Estado e Governo da Organização da Unidade Africana (OUA) em Nairóbi, Quênia, em 27.7.1981.

Posteriormente, a Organização das Nações Unidas (ONU), através da Declaração sobre o Direito ao Desenvolvimento, adotada pela Resolução no 41/128 da Assembleia Geral, em 4.12.1986, proclamou que o direito ao desenvolvimento é um direito humano inalienável, em virtude do qual toda pessoa e todos os povos estão habilitados a participar do desenvolvimento econômico, social, cultural e político, para ele contribuir e dele desfrutar, no qual todos os direitos humanos e liberdades fundamentais possam ser plenamente realizados, ressaltando, inclusive, que a pessoa humana é o sujeito central do desenvolvimento e que deve ser participante ativo e beneficiário do direito ao desenvolvimento.

A Declaração sobre o Direito ao Desenvolvimento ainda define o desenvolvimento como um amplo processo econômico, social, cultural e político, que objetiva a melhoria constante do bem-estar de toda uma população e de todos os indivíduos com base em sua participação ativa, livre e significativa no desenvolvimento.

Em 1993, a Declaração e Programa de Ação de Viena das Nações Unidas reafirmou o direito ao desenvolvimento como um direito universal, fundamental e inalienável do homem, cuja pessoa humana é o sujeito central do desenvolvimento.

O direito ao desenvolvimento sustentável está consagrado no âmbito internacional, em especial no sistema global de direitos humanos. No que toca ao plano interno brasileiro, o art. 3o, inc. II, da Constituição Federal estabelece que é objetivo precípuo da República Federativa do Brasil garantir o desenvolvimento nacional e, por outro lado, em seu art. 225, inspirando-se nos documentos internacionais

\footnotetext{
27 Etienne-R. Mbaya foi, no ano de 1972, o pioneiro na formulação do hoje conhecido “direito ao desenvolvimento". Ver, nesse sentido as observações de BONAVIDES, Paulo. Curso de direito constitucional. 26. ed. São Paulo: Malheiros, 2011. p. 570.
} 
de proteção ao meio ambiente, em especial a Declaração de Estocolmo de 1972, assegura o direito ao meio ambiente ecologicamente equilibrado.

0 art. 225 da Constituição da República revela estreita vinculação com o art. 5o do mesmo diploma normativo, uma vez que este estabelece como garantia fundamental o direito à vida, bem maior que merece ampla proteção do Estado. Assim, se a preservação ambiental é condição sine qua non para a sadia qualidade de vida, conclui-se que a tutela do meio ambiente é imprescindível para o exercício efetivo da garantia fundamental que é a proteção da pessoa humana.

O direito ao meio ambiente ecologicamente equilibrado está diretamente fulcrado no princípio da dignidade da pessoa humana, porque essencial à sadia qualidade de vida e à própria existência humana. Não há que se falar em dignidade humana se não houver condições bióticas e abióticas favoráveis ao bem-estar, à saúde e à vida humana, isto é, que proporcionem ao homem uma sadia qualidade de vida.

Em homenagem aos princípios da unidade da Constituição e da concordância prática das normas constitucionais, chega-se à conclusão que o legislador constituinte fez clara escolha pelo desenvolvimento sustentável porque não se pode promover o desenvolvimento desvinculado da dignidade humana e da proteção ao meio ambiente.

A Constituição Federal reservou inteiramente o Título II aos Direitos e Garantias Fundamentais, nele consagrando um leque amplo e extenso de direitos fundamentais do ser humano, classificando-os em cinco espécies: a) direitos e deveres individuais; b) direitos e deveres coletivos; c) direitos sociais; d) direitos à nacionalidade; e) direitos políticos.

No entanto, o rol do referido Título II da Carta Magna não é exaustivo, mas

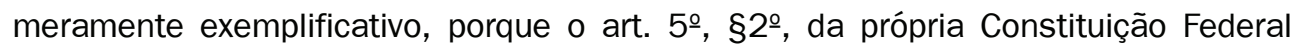
ressalva que "os direitos e garantias expressos nesta Constituição não excluem outros decorrentes do regime e dos princípios por ela adotados, ou dos tratados internacionais em que a República Federativa do Brasil seja parte".

Os direitos fundamentais não são apenas aqueles consagrados formalmente na Constituição, pois a Carta Magna admite a existência de outros direitos fundamentais não inseridos no rol do Título II, reconhecendo, destarte, a existência dos chamados direitos materialmente fundamentais.

Os direitos fundamentais podem ser classificados em direitos formalmente fundamentais e direitos materialmente fundamentais. Serão formalmente fundamentais os direitos expressamente incorporados no catálogo dos direitos fundamentais da Constituição. Por sua vez, os direitos materialmente fundamentais poderão ser identificados a partir do conceito aberto de direitos fundamentais adotado pelo art. 5ㅇ, §ํㅡ, da Constituição Federal, que possibilita o reconhecimento de direitos fundamentais positivados em outras partes do texto constitucional ou em tratados internacionais e até mesmo na identificação de direitos fundamentais não escritos 
ou implícitos na Constituição, que sejam decorrentes do regime e princípios por ela adotados. ${ }^{28}$

A identificação, bem como a caracterização de um direito materialmente dotado de fundamentalidade, não são tarefas fáceis para o intérprete e aplicador do direito, pois tais constatações não decorrem apenas da simples leitura do Texto Constitucional, na medida em que poderão existir outros direitos fundamentais dispersos no corpo da Constituição, positivados em tratados internacionais ou consagrados em princípios não assentados formalmente na Constituição da República.

A definição de direito fundamental proposta por Ingo Wolfgang Sarlet permite ao intérprete a identificação e, consequentemente, a efetivação e a proteção de direitos fundamentais exclusivamente materiais, isto é, não consagrados expressamente no catálogo do Título II da Constituição Federal e fulcrados na dignidade humana. ${ }^{29}$

A dignidade da pessoa humana não é, ela mesma, um direito fundamental, ${ }^{30}$ mas, enquanto princípio estruturante e fundamental do Estado brasileiro, é a fonte e o fundamento dos direitos fundamentais e dos direitos humanos, ${ }^{31}$ atuando, portanto, como critério de identificação de direitos materialmente fundamentais eventualmente existentes na ordem jurídica do Brasil.

Assim, reconhecem-se direitos que, apesar de não consagrados formalmente no rol do Título II da Constituição Federal, por seu conteúdo, importância e significado, podem ser considerados fundamentais e, por isso mesmo, inseridos, ainda que implicitamente, na Carta Constitucional, produzindo todos os efeitos jurídicos como se direitos formalmente fundamentais fossem.

Com base nessas premissas, pode-se concluir que o desenvolvimento sustentável é legítimo direito fundamental da pessoa humana implícito na Constituição Federal de $1988,{ }^{32}$ pois decorrente de um processo contínuo e automático de transformação concomitantemente social, político e econômico que promove, além do avanço econômico, a realização da dignidade da pessoa humana, mediante o aumento da qualidade de vida das pessoas e do bem-estar da população, e protege o meio ambiente para as presentes e futuras gerações.

Ademais, não se pode olvidar que o direito ao desenvolvimento sustentável é princípio consagrado no ordenamento jurídico pátrio pelas razões antes aduzidas,

28 SARLET, Ingo Wolfgang. A eficácia dos direitos fundamentais. 8. ed. Porto Alegre: Livraria do Advogado, 2007. p. 85.

29 SARLET, Ingo Wolfgang. A eficácia dos direitos fundamentais. 8. ed. Porto Alegre: Livraria do Advogado, 2007. p. 91.

30 SARLET, Ingo Wolfgang. Dignidade da pessoa humana e direitos fundamentais na Constituição Federal de 1988. 9. ed. Porto Alegre: Livraria do Advogado, 2012. p. 84.

31 SARLET, Ingo Wolfgang. Dignidade da pessoa humana e direitos fundamentais na Constituição Federal de 1988. 9. ed. Porto Alegre: Livraria do Advogado, 2012. p. 95.

32 HACHEM, Daniel Wunder. A noção constitucional de desenvolvimento para além do viés econômico: reflexos sobre algumas tendências do direito público brasileiro. $A \& C$ - Revista de Direito Administrativo \& Constitucional, Belo Horizonte, ano 13, n. 53, p. 133-168, jul./set. 2013. p. 154. 
todas em perfeita sintonia com a base principiológica em que assenta a Carta Magna vigente, que reconhece direitos de fraternidade ou de solidariedade, seja a partir do compromisso preambular que assume o Estado brasileiro, seja tendo em vista o objetivo fundamental gravado no inc. I, do art. 3ํㅡ, de construção de uma sociedade livre, justa e solidária. ${ }^{33}$

\section{Edificações públicas sustentáveis}

A construção e o uso de prédios públicos e particulares são um dos maiores consumidores de recursos naturais no meio ambiente, utilizando $16,6 \%$ do fornecimento mundial de água pura, $25 \%$ de sua colheita de madeira e $40 \%$ de seus combustíveis fósseis e materiais manufaturados. ${ }^{34} \mathrm{O}$ ramo da construção civil responde também pelo processo de contaminação atmosférica, sendo responsável por grande parcela das emissões de $\mathrm{CO}_{2}$, principal gás responsável pelo efeito estufa, ${ }^{35}$ de modo que não se pode conceber a existência de desenvolvimento sustentável sem a construção e o uso de empreendimentos imobiliários sustentáveis.

Segundo a Agenda 21 for Sustainable Construction in Developing Countries, a preocupação com a crise ecológica deve se refletir na construção e no uso de edificações urbanas, porque produzem externalidades ambientais e sociais negativas. ${ }^{36}$ Tais atividades devem ser sustentáveis, com baixo impacto socioambiental.

As construções sustentáveis, também chamadas de verdes, visam ao "aumento das oportunidades ambientais às gerações futuras, consistindo numa moderna estratégia ambiental, direcionada à produção de empreendimentos mais seguros e saudáveis", ${ }^{37}$ o que pressupõem a adoção de práticas e atitudes que contemplem os aspectos econômico, social e ambiental do desenvolvimento sustentável em

33 MACHADO, Carlos Augusto Alcântara. A garantia constitucional da fraternidade: constitucionalismo fraternal. 2014. 271 f. Tese (Doutorado em Direito) - Curso de Pós-Graduação em Direito, Pontifícia Universidade Católica de São Paulo. São Paulo, 2014. p. 184.

34 LAMBERTS, Roberto et al. Sustentabilidade nas edificações: contexto internacional e algumas referências brasileiras na área. Disponível em: <http://www.labeee.ufsc.br/sites/default/files/documents/sustentabili dade_nas_edificacoes_contexto_internacional_e_algumas_referencias_brasileiras_na_areasustentabilidade_ nas_edificacoes_contexto_internacional_e_algumas_referencias_brasileiras_na_area.pdf>. Acesso em: 22 fev. 2015.

35 LAMBERTS, Roberto et al. Sustentabilidade nas edificações: contexto internacional e algumas referências brasileiras na área. Disponível em: <http://www.labeee.ufsc.br/sites/default/files/documents/sustentabili dade_nas_edificacoes_contexto_internacional_e_algumas_referencias_brasileiras_na_areasustentabilidade_ nas_edificacoes_contexto_internacional_e_algumas_referencias_brasileiras_na_area.pdf $>$. Acesso em: $2 \overline{2}$ fev. 2015.

36 INTERNATIONAL COUNCIL FOR RESEARCH AND INNOVATION IN BUILDING AND CONSTRUCTION. Agenda 21 for sustainable construction in developing countries: a discussion document. Pretoria: CSIR Building and Construction Technology, 2002. p. 1.

37 FLORIM, Leila Chagas; QUELHAS, Osvaldo Luiz Gonçalves. Contribuição para a construção sustentável: características de um projeto habitacional eco-eficiente. Engevista, Niterói, v. 6, n. 3, p. 121-132, 2004. p. 125. 
todas as etapas da obra e da vida útil das construções, ${ }^{38}$ ou seja, na concepção, no desenvolvimento dos projetos básico e executivo, na construção, no uso e ocupação do empreendimento e na demolição. ${ }^{39}$

Os princípios básicos da construção sustentável estão relacionados ao canteiro de obras de baixo impacto ambiental, à qualidade ambiental interna e externa de empreendimento, à redução do consumo de energia elétrica, à redução do consumo de água, ao aproveitamento de condições naturais locais, à implantação e análise do entorno, à reciclagem, reutilização e redução os resíduos sólidos, à gestão da manutenção e conservação do edifício, ao conforto higrotérmico no inverno e no verão, ao conforto acústico na execução e no uso da obra, ao conforto visual, ao conforto olfativo através da limitação de odores desagradáveis e à qualidade sanitária do ar e da água. ${ }^{40}$

O Conselho Brasileiro de Construção Sustentável ${ }^{41}$ recomenda que as edificações sustentáveis devam observar alguns procedimentos para a redução dos impactos socioambientais causados pelas obras da construção civil, dentre as quais se destacam: a) especificação de equipamentos com menor consumo e melhor eficiência possível na utilização do gás natural para todos os fins; b) automatização de transporte vertical com otimização de carga e menor consumo energético possível com a adoção de sistemas eficientes como o ADC (antecipação de chamadas); c) iluminação de baixo consumo energético nas áreas comuns de uso contínuo, e iluminação "incandescente" com acionadores por sensor de presença nas áreas de uso esporádico ou intermitente; d) planejamento do consumo energético e utilização de equipamentos para gerar energia em períodos de pico; e) melhor aproveitamento possível da iluminação natural, levando-se em conta a necessidade do seu controle; f) melhor condição de conforto térmico evitando a incidência da radiação solar direta através da adoção de soluções arquitetônicas tipo brises-soleil, venezianas, telas termo-screen externas, prateleiras de luz, vidros especiais que dispensam o uso de brises etc.; g) implementação e otimização de ventilação natural; h) adoção preferencial de acabamentos claros nas áreas de grande incidência de luz solar; i) tratamento das coberturas do edifício analisando a possibilidade de implementação

\footnotetext{
38 MEDEIROS, Mirna de Lima et al. Adoção da certificação leed em meios de hospedagem: esverdeando a hotelaria?. Revista de Administração de Empresas, São Paulo, v. 52, n. 2, p. 179-192, mar./abr. 2012. p. 182.

39 SALGADO, Mônica Santos; CHATELET, Alain; FERNANDEZ, Pierre. Produção de edificações sustentáveis: desafios e alternativas. Revista Ambiente Construído, Porto Alegre, v. 12, n. 4, p. 81-99, out./dez. 2012. p. 83.

40 SALGADO, Mônica Santos; CHATELET, Alain; FERNANDEZ, Pierre. Produção de edificações sustentáveis: desafios e alternativas. Revista Ambiente Construído, Porto Alegre, v. 12, n. 4, p. 81-99, out./dez. 2012. p. 86-87.

41 O Conselho Brasileiro de Construção Sustentável é uma associação sem fins lucrativos que tem por finalidade contribuir para o desenvolvimento sustentável por meio da geração e disseminação de conhecimento e da mobilização da cadeia produtiva da construção civil e de seus clientes e consumidores.
} 
de áreas verdes ou, caso essa solução não seja possível, utilização de pinturas reflexivas para diminuir a absorção de calor para o edifício; e j) uso de soluções alternativas de produção de energia, como a eólica ou a solar, de acordo com as condições locais. ${ }^{42}$

E mais, recomenda-se ainda a captação, armazenamento e tratamento de águas pluviais para reutilização na irrigação, limpeza, refrigeração, sistema de combate a incêndio e demais usos permitidos para água não potável, a utilização de bacias acopladas e válvulas especiais com o fluxo opcional por descarga, ou de sistemas a vácuo, o reaproveitamento das águas de lavagem, com tratamento local, para utilização sanitária, a utilização de torneiras com acionamento eletrônico ou temporizador por pressão em todas as aplicações passíveis, a maximização na especificação de materiais sustentáveis objetivando o maior volume possível de utilização de materiais certificados, de manejo sustentável e recicláveis, o planejamento para maior durabilidade possível nas especificações visando à alta performance e evitando obsolescência prematura, a utilização de materiais cujos processos de extração de matérias-primas, beneficiamento, produção, armazenamento e transporte causem menor índice de danos ao meio ambiente nem estejam baseados em condições de trabalho indignas para os operários. ${ }^{43}$

A noção de construção sustentável deve estar, portanto, presente em todo o ciclo de vida do empreendimento. É necessário um detalhamento do que pode ser feito em cada fase da obra, demonstrando aspectos e impactos ambientais e como estes itens devem ser trabalhados para que se caminhe para um empreendimento que seja: uma ideia sustentável, uma implantação sustentável e um uso sustentável. ${ }^{44}$

Mas o Estado tem a obrigação de somente edificar prédios públicos sustentáveis ou se trata de mera discricionariedade administrativa?

o legislador constituinte originário estabeleceu, dentre os princípios estruturantes do Estado brasileiro, o princípio do Estado Democrático de Direito, que dada a sua forte carga axiológica e normativa, deve nortear toda a atividade estatal, inclusive a atividade administrativa.

O Estado de Direito tem as suas origens nas revoluções liberais dos séculos XVII e XVIII, notadamente a Revolução Francesa. O Antigo Regime tinha como uma de suas marcas o poder ilimitado do soberano e, por via de consequência do Estado, o que dava ensejo, à evidência, a práticas arbitrárias.

\footnotetext{
${ }_{42}$ CONSELHO BRASILEIRO DE CONSTRUÇÃO SUSTENTÁVEL. Disponível em: <http://www.cbcs.org.br/ comitestematicos/projeto/artigos/recomendacoes_basicas-asbea.php>. Acesso em: 17 jan. 2015.

43 CONSELHO BRASILEIRO DE CONSTRUÇÃO SUSTENTÁVEL. Disponível em: <http://www.cbcs.org.br/ comitestematicos/projeto/artigos/recomendacoes_basicas-asbea.php>. Acesso em: 17 jan. 2015.

44 CÂMARA DA INDÚSTRIA DA CONSTRUÇÃO. Guia de sustentabilidade da construção. Belo Horizonte: FIEMG, 2008. p. 15.
} 
O Estado de Direito nasce para combater a arbitrariedade do Estado Absolutista, impondo limites jurídicos à atuação estatal. Tais limites são impostos pela lei e, sobretudo, pela consagração dos direitos fundamentais da pessoa humana, quais sejam, à época, a liberdade e a propriedade privada da classe burguesa. Enfim, no Estado de Direito há submissão de todos, inclusive do Estado, à Constituição e às leis. Não mais prepondera a vontade do soberano, mas a vontade da lei.

O princípio constitucional do Estado Democrático de Direito tem como corolário lógico o princípio da legalidade, ${ }^{45}$ positivado nos arts. $5^{\circ}$, inc. Il e 37 , caput, ambos da Constituição Federal. 0 princípio do Estado de Direito impõe a submissão de todos às normas jurídicas, ao passo que o princípio da legalidade consiste na ideia de que todo e qualquer ato que emane da Administração Pública deve ter prévia determinação legal, de modo que "não há atividade administrativa lícita no silêncio da lei". ${ }^{46}$

O princípio do Estado de Direito e o princípio da legalidade formam a base do regime jurídico-administrativo. A atuação estatal deve estar pautada, portanto, na Constituição Federal e na legislação infraconstitucional como requisito de validade e legitimidade. Desse modo, extrai-se que é dever estatal garantir a efetividade do direito fundamental ao desenvolvimento sustentável, notadamente por meio de políticas públicas.

Os direitos fundamentais revelam duas dimensões ou perspectivas, a subjetiva e a objetiva, na medida em que se apresentam como direitos subjetivos e como valores e princípios básicos e fundamentais da ordem jurídica.

Sob o aspecto subjetivo, os direitos fundamentais autorizam o seu titular a exigir judicialmente a produção de seus efeitos práticos específicos. ${ }^{47}$ Abre-se assim a possibilidade de as pessoas demandarem em juízo a efetividade e concretização de seus direitos fundamentais eventualmente lesados.

Os direitos fundamentais constituem, sob a dimensão objetiva, um sistema de valores básicos de um ordenamento jurídico, que serve de diretriz para a atuação de todas as esferas de governo do Estado. Os direitos fundamentais, calcados na dignidade da pessoa humana, são a base da ordem jurídica de um Estado democrático, já que "não se pode falar em propriamente em regimes democráticos sem que se admita também a conformação da ordem econômica e social aos fins de construção da existência digna". 48

\footnotetext{
45 MELLO, Rafael Munhoz de. Princípios constitucionais de direito administrativo sancionador. as sanções administrativas à luz da Constituição Federal de 1988. São Paulo: Malheiros, 2007. p. 96.

46 MELLO, Rafael Munhoz de. Princípios constitucionais de direito administrativo sancionador. as sanções administrativas à luz da Constituição Federal de 1988. São Paulo: Malheiros, 2007. p. 97.

47 SARLET, Ingo Wolfgang. A eficácia dos direitos fundamentais. 8. ed. Porto Alegre: Livraria do Advogado, 2007. p. 180.

48 CASTILHO, Ricardo. Justiça social e distributiva: desafios para concretizar direitos sociais. São Paulo: Saraiva, 2009. p. 61.
} 
Nesse diapasão, o direito fundamental ao desenvolvimento sustentável tem eficácia vertical e horizontal, de modo que vincula o Estado e os particulares.

Ademais, a qualificação de um direito fundamental em princípio jurídico é possível porque não se trata de conceitos antitéticos e reciprocamente excludentes, na medida em que as normas constitucionais definidoras de direitos fundamentais são eminentemente principiológicas. ${ }^{49}$

Nessa linha de raciocínio, o princípio do desenvolvimento sustentável ou simplesmente princípio da sustentabilidade é um princípio constitucional implícito, incorporado ao ordenamento jurídico brasileiro, de aplicabilidade direta e imediata, com vistas a compelir um desenvolvimento econômico compatível com a dignidade da pessoa humana, os direitos sociais e o meio ambiente. ${ }^{50}$

Hodiernamente, não mais se discute a força normativa da Constituição. A Carta Magna é norma jurídica e, por isso mesmo, seus preceitos são obrigatórios e vinculativos, ${ }^{51}$ motivo pelo qual o princípio constitucional implícito da sustentabilidade obriga ética e juridicamente o Estado e os particulares a promoverem a sustentabilidade econômica, social e ambiental. ${ }^{52}$

A efetividade do princípio/direito ao desenvolvimento sustentável depende da realização de prestações fáticas e jurídicas, notadamente de políticas públicas, destinadas a promover os seus três pilares, quais sejam, o social, o econômico e o ambiental..$^{53}$

O desenvolvimento sustentável deve promover a justiça social, a distribuição territorial equilibrada de assentamentos humanos, o crescimento econômico contínuo e duradouro, a governabilidade política e a conservação do meio ambiente, ${ }^{54}$ objetivos que dependem do Estado para serem alcançados.

Os entes estatais devem atuar, portanto, no sentido de promover o desenvolvimento sustentável. Não se trata, repita-se, de opção política de sustentabilidade, mas de dever constitucional e legal. Nesse contexto, a Lei oㅡ 12.349, de 15.12.2010, alterou 0 art. oo da Lei $n$ o 8.666/93, incluindo, textualmente, entre as finalidades da licitação, a promoção do desenvolvimento nacional sustentável.

O processo licitatório está sustentado sob três pilares, quais sejam, o respeito à isonomia, a seleção da proposta mais vantajosa para a administração e a promoção do desenvolvimento nacional sustentável, de modo que não se destina somente a

\footnotetext{
49 SARLET, Ingo Wolfgang. Dignidade da pessoa humana e direitos fundamentais na Constituição Federal de 1988. 9. ed. Porto Alegre: Livraria do Advogado, 2012. p. 83.

50 FREITAS, Juarez. Sustentabilidade: direito ao futuro. 2. ed. Belo Horizonte: Fórum, 2012. p. 51.

51 HESSE, Konrad. A força normativa da Constituição. Tradução de Gilmar Ferreira Mendes. Porto Alegre: Sérgio Antônio Frabris Editor, 1991. p. 19.

52 FREITAS, Juarez. Sustentabilidade: direito ao futuro. 2. ed. Belo Horizonte: Fórum, 2012. p. 51,

53 FERREIRA, Daniel; GIUSTI, Anna Flávia Camilli Oliveira. A licitação pública como instrumento de concretização do direito fundamental ao desenvolvimento nacional sustentável. A\&C - Revista de Direito Administrativo \& Constitucional, Belo Horizonte, ano 12, n. 48, p. 177-193, abr./jun. 2012. p. 182.

54 SACHS, Ignacy. Caminhos para o desenvolvimento sustentável. Rio de Janeiro: Garamond, 2009. p. 71-72.
} 
obter a proposta economicamente mais proveitosa para a Administração Pública, mas tem também o objetivo legal de promover o desenvolvimento sustentável, no sentido de que a definição do objeto da contratação, a avaliação das propostas e a escolha do contratado devem levar em consideração critérios de sustentabilidade econômica, social e ambiental.

A licitação pública serve, portanto, de instrumento de concretização dos objetivos fundamentais da República Federativa do Brasil, entre os quais o desenvolvimento nacional sustentável, "que pressupõe o desenvolvimento do indivíduo, da coletividade e da própria nação, num cenário que inexoravelmente alia aspectos econômicos, ambientais e sociais". 55

Outrossim, o objetivo da Lei $n=12.349$, de 15.12.2010, ao alterar a redação do art. 3o da Lei no 8.666/93, não foi propriamente o de incluir, dentre as finalidades da licitação, a promoção do desenvolvimento nacional sustentável, mas sim o de estabelecer que a promoção do desenvolvimento sustentável é escopo a ser buscado por meio do contrato administrativo. ${ }^{56}$

A licitação é procedimento administrativo através do qual a Administração Pública seleciona a proposta mais vantajosa dentre as formuladas pelos licitantes. Antecede à contratação administrativa propriamente dita, enquanto que a aquisição de bens ou serviços e a delegação de serviços públicos ocorrem efetivamente com a celebração do contrato administrativo. ${ }^{57}$ Nesse diapasão, a promoção do desenvolvimento sustentável é desiderato das contratações públicas. ${ }^{58}$

Assim, pode-se afirmar que, mesmo nos casos de contratação direta, ou seja, de dispensa ou de inexigibilidade de licitação, o princípio do desenvolvimento sustentável deverá nortear a contratação pública. Vale dizer: as contratações administrativas, precedidas ou não de licitação, deverão ser sustentáveis, isto é, devem “buscar equilibrar as metas econômicas com os aspectos ambientais e sociais, dada conhecida fórmula do triple bottom line: profit, people and planet". 59

55 FERREIRA, Daniel; GIUSTI, Anna Flávia Camilli Oliveira. A licitação pública como instrumento de concretização do direito fundamental ao desenvolvimento nacional sustentável. A\&C - Revista de Direito Administrativo \& Constitucional, Belo Horizonte, ano 12, n. 48, p. 177-193, abr./jun. 2012. p. 191.

56 JUSTEN FILHO, Marçal. Desenvolvimento nacional sustentado: contratações administrativas e o regime introduzido pela lei 12.349. Informativo Justen, Pereira, Oliveira e Talamini, Curitiba, n. 50, abr. 2011. Disponivel em: <http://www.justen.com.br//informativo.php?\&informativo=50\&artigo=1077\&l=pt>. Acesso em: 20 fev. 2015.

57 JUSTEN FILHO, Marçal. Desenvolvimento nacional sustentado: contratações administrativas e o regime introduzido pela lei 12.349. Informativo Justen, Pereira, Oliveira e Talamini, Curitiba, n. 50, abr. 2011. Disponível em: <http://www.justen.com.br//informativo.php?\&informativo=50\&artigo=1077\&l=pt>. Acesso em: 20 fev. 2015.

58 JUSTEN FILHO, Marçal. Desenvolvimento nacional sustentado: contratações administrativas e o regime introduzido pela lei 12.349. Informativo Justen, Pereira, Oliveira e Talamini, Curitiba, n. 50, abr. 2011. Disponível em: <http://www.justen.com.br//informativo.php?\&informativo=50\&artigo=1077\&l=pt>. Acesso em: 20 fev. 2015.

59 NOHARA, Irene Patrícia. Desafios jurídicos das parcerias público-privadas (PPPs) e desenvolvimento nacional sustentável. Revista de Direito Econômico e Socioambiental, Curitiba, v. 5, n. 2, p. 184-203, jul./dez. 2014. p. 189. 
Enfim, a realização de licitações e contratações administrativas sustentáveis é obrigação estatal de estatura constitucional e legal. Inclusive, nos casos de execução direta de obras e serviços pelo Estado, ou seja, pelos próprios meios, sem a intervenção de terceiros, há a obrigatoriedade de tais atividades administrativas serem sustentáveis, em razão, como ressaltado alhures, da força normativa da Constituição e da eficácia vertical dos direitos fundamentais.

Ademais, o exercício da atividade estatal, inclusive a função administrativa, deve ser atrelado ao atendimento do interesse público primário, ${ }^{60}$ apresentando-se, portanto, como limite à discricionariedade administrativa. 0 gestor público tem o dever de agir em conformidade com o interesse público primário, pois, repita-se, a atuação do Estado deve ser voltada exclusivamente à satisfação do interesse público primário.

A expressão interesse público compreende o interesse público primário e o interesse público secundário, que não se confundem. 0 primário pode ser identificado com o interesse geral da sociedade ou da coletividade, ao passo que o secundário se refere ao interesse da administração, ou seja, ao modo como os agentes públicos veem o interesse público. ${ }^{61}$

Tal distinção evidencia que nem sempre coincidem o interesse público primário e o secundário, ${ }^{62}$ de modo que somente é lícito à Administração Pública perseguir o interesse público secundário em compasso com o primário, ${ }^{63}$ isto é, o interesse secundário "só pode ser validamente perseguido pelo Estado quando coincidente com o interesse público primário". ${ }^{64}$

Revela-se ser de interesse da coletividade a promoção do desenvolvimento sustentável porque realiza a justiça social e protege o meio ambiente sadio para as presentes e futuras gerações. Em suma: a concretização do desenvolvimento sustentável se traduz em interesse público primário ${ }^{65} \mathrm{e}$, por consequência, limite à discricionariedade da Administração Pública.

A Administração Pública não pode, por ocasião da construção de edifícios públicos, levar em consideração unicamente fatores econômicos, mas conjugá-los com as dimensões social e ambiental do desenvolvimento sustentável, isto é, com os custos socioambientais envolvidos. ${ }^{66}$

60 BANDEIRA DE MELLO, Celso Antônio. Discricionariedade e controle jurisdicional. 2. ed. São Paulo: Malheiros, 2010. p. 54.

61 BANDEIRA DE MELLO, Celso Antônio. Curso de direito administrativo. 26. ed. São Paulo: Malheiros, 2009. p. 72.

62 MAZZILLI, Hugo Nigro. Regime jurídico do Ministério Público. 7. ed. São Paulo: Saraiva, 2013. p. 119.

63 VALIM, Rafael. Contratação pública e sustentabilidade. In: MARRARA, Thiago (Org.). Direito administrativo: transformações e tendências. São Paulo: Almedina, 2014. p. 522.

64 BANDEIRA DE MELLO, Celso Antônio. Curso de direito administrativo. 26. ed. São Paulo: Malheiros, 2009. p. 99.

65 MARRARA, Thiago. O conteúdo do princípio da moralidade: probidade, razoabilidade e cooperação. In: MARRARA, Thiago (Org.). Princípios de direito administrativo. São Paulo: Atlas, 2012. p. 162.

66 VALIM, Rafael. Contratação pública e sustentabilidade. In: MARRARA, Thiago (Org.). Direito administrativo: transformações e tendências. São Paulo: Almedina, 2014. p. 522. 
Aliás, apesar de os custos da adoção de edificações sustentáveis, em comparação a construções convencionais do mesmo padrão, serem, em curto prazo, superiores em até $6,5 \%$, há significativa redução dos gastos em longo prazo e otimização do desempenho financeiro, gerando uma economia média de $U \$ 538,15$ a U\$ 99,60 por metro quadrado construído. ${ }^{67}$

Os custos sociais e ambientais do empreendimento predial são menos visíveis do que os econômicos, de modo que se deve levar em consideração o custo ao longo do ciclo de vida do edifício público, pois os empreendimentos sustentáveis pagam-se por si mesmos a médio prazo, propiciando, inclusive, o retorno do investimento inicial para a sua construção. ${ }^{68}$

Assim, os prédios públicos construídos, direta ou indiretamente, pelo Estado devem ser sustentáveis porque, além de se constituir em obrigação estatal de estatura constitucional e legal, promovem as diretrizes normativas e científicas de sustentabilidade econômica, social e ambiental e atendem ao interesse público primário.

\section{Considerações finais}

A Constituição Federal de 1988 alçou o direito ao desenvolvimento sustentável à categoria de direito fundamental do homem, uma vez que não há que se falar em respeito à dignidade humana se não houver a promoção da justiça redistributiva, a maximização da eficácia dos direitos sociais e a implementação de uma justiça ambiental intergeracional que permita às futuras gerações o acesso a um meio ambiente sadio e necessário à qualidade de vida.

O direito fundamental ao desenvolvimento sustentável constitui, sob a dimensão objetiva, um dos valores básicos do ordenamento jurídico brasileiro, servindo de diretriz para a atuação de todas as esferas de governo do Estado. Assim, a Constituição Federal impôs ao Estado o dever fundamental de garantir o desenvolvimento sustentável, subtraindo do Administrador Público qualquer juízo de conveniência e oportunidade sobre a sua concretização ou não, isto é, não está na livre disposição dos poderes públicos decidir se o desenvolvimento sustentável deve ou não ser promovido.

Ademais, a Administração Pública tem o dever de agir em conformidade com o interesse público primário, sendo que a concretização do desenvolvimento

67 MEDEIROS, Mirna de Lima et al. Adoção da certificação leed em meios de hospedagem: esverdeando a hotelaria?. Revista de Administração de Empresas, São Paulo, v. 52, n. 2, p. 179-192, mar./abr. 2012. p. 182.

68 GARÉ, José Carlos. Contribuições da construção civil brasileira para o desenvolvimento sustentável. $164 \mathrm{f}$. Dissertação (Mestrado em Administração) - Programa de Pós-Graduação em Administração da Universidade Municipal de São Caetano do Sul. São Caetano do Sul, 2011. p. 32. 
sustentável se traduz em interesse público primário e, por consequência, limita a discricionariedade administrativa.

Nesse cenário, a Administração Pública não pode, por ocasião da construção de edifícios públicos, levar em consideração unicamente fatores econômicos, mas conjugá-los com as dimensões social e ambiental do desenvolvimento sustentável.

Assim, o Estado é obrigado a construir edifícios públicos verdes porque não há que se falar em desenvolvimento sustentável sem edificações econômica, social e ambientalmente sustentáveis.

Public green buildings: administrative discretion or duty legal and constitutional obligation?

Abstract: The construction and the use of public buildings cause serious negative effects on the environment because they use a lot of natural resources in its construction and have high impact on the consumption of electricity and water and solid waste. Therefore, this article aims to present the main, from a doctrinal and legislative research, arguments favorable to the effect that the construction and use of public buildings should occur in line with sustainable development. Thus, it will examine the concept of sustainable development, its recognition as a fundamental right of the human person, the idea of green buildings and the state duty to build up sustainable public buildings.

Keywords: Sustainability. Green buildings. Public buildings. State duty.

\section{Referências}

ANJOS FILHO, Robério Nunes dos. Direito ao desenvolvimento. São Paulo: Saraiva, 2013.

BANDEIRA DE MELLO, Celso Antônio. Curso de direito administrativo. 26. ed. São Paulo: Malheiros, 2009.

BANDEIRA DE MELLO, Celso Antônio. Discricionariedade e controle jurisdicional. 2. ed. São Paulo: Malheiros, 2010.

BAUMAN, Zygmunt. Vida para o consumo: a transformação das pessoas em mercadoria. Rio de Janeiro: Zahar, 2008.

BONAVIDES, Paulo. Curso de direito constitucional. 26. ed. São Paulo: Malheiros, 2011.

BOUDRILLARD, Jean. A sociedade de consumo. 3. ed. Lisboa: Edições 70, 2011.

CÂMARA DA INDÚSTRIA DA CONSTRUÇÃO. Guia de sustentabilidade da construção. Belo Horizonte: FIEMG, 2008.

CAPRA, Fritoj. A teia da vida: uma nova compreensão científica dos sistemas vivos. São Paulo: Cultrix, 2006.

CAPRA, Fritoj. As conexões ocultas: ciência para uma vida sustentável. São Paulo: Cultrix, 2005.

CASTILHO, Ricardo. Justiça social e distributiva: desafios para concretizar direitos sociais. São Paulo: Saraiva, 2009.

COMISSÃO MUNDIAL SOBRE MEIO AMBIENTE E DESENVOLVIMENTO. Nosso futuro comum. 2. ed. Rio de Janeiro: Editora da Fundação Getúlio Vargas, 1991. 
DALY, Herman E. Economics in a full world. Scientific American, EUA, v. 293, n. 3, p. 100-107, set. 2005.

FAJARDO, Elias. Consumo consciente, comércio justo: conhecimento e cidadania como fatores econômicos. Rio de Janeiro: Senac Nacional, 2010.

FERREIRA, Daniel; GIUSTI, Anna Flávia Camilli Oliveira. A licitação pública como instrumento de concretização do direito fundamental ao desenvolvimento nacional sustentável. A\&C - Revista de Direito Administrativo \& Constitucional, Belo Horizonte, ano 12, n. 48, p. 177-193, abr./jun. 2012.

FLORIM, Leila Chagas; QUELHAS, Osvaldo Luiz Gonçalves. Contribuição para a construção sustentável: características de um projeto habitacional eco-eficiente. Engevista, Niterói, v. 6, n. 3, p. 121-132, 2004.

FOSTER, John Bellamy. A ecologia em Marx: materialismo e natureza. Rio de Janeiro: Civilização Brasileira, 2005.

FREITAS, Juarez. Sustentabilidade: direito ao futuro. 2. ed. Belo Horizonte: Fórum, 2012.

GARBADO, Emerson. Interesse público e subsidiariedade: o Estado e a sociedade civil para além do bem e do mal. Belo Horizonte: Fórum, 2009.

GARÉ, José Carlos. Contribuições da construção civil brasileira para o desenvolvimento sustentável. 164 f. Dissertação (Mestrado em Administração) - Programa de Pós-Graduação em Administração da Universidade Municipal de São Caetano do Sul. São Caetano do Sul, 2011.

GIDDENS, Anthony. As consequências da modernidade. Tradução de Raul Fiker. São Paulo: Unesp, 1991.

HACHEM, Daniel Wunder. A noção constitucional de desenvolvimento para além do viés econômico: reflexos sobre algumas tendências do direito público brasileiro. A\&C - Revista de Direito Administrativo \& Constitucional, Belo Horizonte, ano 13, n. 53, p. 133-168, jul./set. 2013.

HARDING, Stephan. Terra viva: ciência, intuição e a evolução de Gaia - Para uma nova compreensão da vida em nosso planeta. São Paulo: Cultrix, 2008.

HESSE, Konrad. A força normativa da Constituição. Tradução de Gilmar Ferreira Mendes. Porto Alegre: Sérgio Antônio Frabris Editor, 1991.

INTERNATIONAL COUNCIL FOR RESEARCH AND INNOVATION IN BUILDING AND CONSTRUCTION. Agenda 21 for sustainable construction in developing countries: a discussion document. Pretoria: CSIR Building and Construction Technology, 2002.

JUSTEN FILHO, Marçal. Desenvolvimento nacional sustentado: contratações administrativas e o regime introduzido pela lei 12.349. Informativo Justen, Pereira, Oliveira e Talamini, Curitiba, n. 50, abr. 2011. Disponível em: <http://www.justen.com.br//informativo.php?\&informativo=50\&artigo=1 077\&l=pt>. Acesso em: 20 fev. 2015.

LAMBERTS, Roberto et al. Sustentabilidade nas edificações: contexto internacional e algumas referências brasileiras na área. Disponível em: <http://www.labeee.ufsc.br/sites/default/files/ documents/sustentabilidade_nas_edificacoes_contexto_internacional_e_algumas_referencias_ brasileiras_na_areasustentabilidade_nas_edificacoes_contexto_internacional_e_algumas_referencias_ brasileiras_na_area.pdf>. Acesso em: 22 fev. 2015.

MACHADO, Carlos Augusto Alcântara. A garantia constitucional da fraternidade: constitucionalismo fraternal. 2014. 271 f. Tese (Doutorado em Direito) - Curso de Pós-Graduação em Direito, Pontificia Universidade Católica de São Paulo. São Paulo, 2014.

MARRARA, Thiago. 0 conteúdo do princípio da moralidade: probidade, razoabilidade e cooperação. In: MARRARA, Thiago (Org.). Princípios de direito administrativo. São Paulo: Atlas, 2012.

MAZZILLI, Hugo Nigro. Regime jurídico do Ministério Público. 7. ed. São Paulo: Saraiva, 2013. 
MEDEIROS, Mirna de Lima et al. Adoção da certificação leed em meios de hospedagem: esverdeando a hotelaria?. Revista de Administração de Empresas, São Paulo, v. 52, n. 2, p. 179-192, mar./abr. 2012.

MELLO, Rafael Munhoz de. Princípios constitucionais de direito administrativo sancionador. as sanções administrativas à luz da Constituição Federal de 1988. São Paulo: Malheiros, 2007.

MINISTÉRIO DO MEIO AMBIENTE. Declaração do Rio sobre meio ambiente e desenvolvimento. Disponível em: <www.mma.gov.br/port/sdi/ea/documentos/convs/decl_rio92.pdf>. Acesso em: 10 mar. 2015.

MORIN, Edgar. A via para o futuro da humanidade. Rio de Janeiro: Bertrand Brasil, 2013.

NOHARA, Irene Patrícia. Desafios jurídicos das parcerias público-privadas (PPPs) e desenvolvimento nacional sustentável. Revista de Direito Econômico e Socioambiental, Curitiba, v. 5, n. 2, p. 184-203, jul./dez. 2014.

ORGANIZAÇÃO DAS NAÇÕES UNIDAS. Resolução 66/288. o futuro que queremos. Disponível em: <http://www.un.org/ga/search/view_doc.asp?symbol=A/RES/66/288\&Lanh=E >. Acesso em: 3 mar. 2015.

PORTILHO, Fátima. Sustentabilidade ambiental, consumo e cidadania. 2. ed. São Paulo: Cortez, 2010.

RISTER, Carla Abrantkski. Direito ao desenvolvimento: antecedentes, significados e consequências. São Paulo: Renovar, 2007.

SACHS, Ignacy. Caminhos para o desenvolvimento sustentável. Rio de Janeiro: Garamond, 2009.

SACHS, Ignacy. Primeiras intervenções. In: NASCIMENTO, Elimar Pinheiro do; VIANA, João Nildo. Dilemas e desafios do desenvolvimento sustentável no Brasil. Rio de Janeiro: Garamond, 2007.

SALGADO, Mônica Santos; CHATELET, Alain; FERNANDEZ, Pierre. Produção de edificações sustentáveis: desafios e alternativas. Revista Ambiente Construído, Porto Alegre, v. 12, n. 4, p. 81-99, out./dez. 2012.

SARLET, Ingo Wolfgang. A eficácia dos direitos fundamentais. 8. ed. Porto Alegre: Livraria do Advogado, 2007.

SARLET, Ingo Wolfgang. Dignidade da pessoa humana e direitos fundamentais na Constituição Federal de 1988. 9. ed. Porto Alegre: Livraria do Advogado, 2012.

VALIM, Rafael. Contratação pública e sustentabilidade. In: MARRARA, Thiago (Org.). Direito administrativo: transformações e tendências. São Paulo: Almedina, 2014.

Informação bibliográfica deste texto, conforme a NBR 6023:2002 da Associação Brasileira de Normas Técnicas (ABNT):

MACHADO, Carlos Augusto Alcântara; RESENDE, Augusto César Leite de. Edifícios públicos sustentáveis: discricionariedade administrativa ou dever constitucional e legal?. A\&C - Revista de Direito Administrativo \& Constitucional, Belo Horizonte, ano 16, n. 63, p. 165-185, jan./mar. 2016.

Recebido em: 09.06.2015

Aprovado em: 06.10.2015 